\title{
Apigenin inhibits proliferation and invasion, and induces apoptosis and cell cycle arrest in human melanoma cells
}

\author{
GUANGMING ZHAO $^{1 *}$, XIAODONG HAN ${ }^{1 *}$, WEI CHENG $^{2}$, JING NI $^{1}$, \\ YUNFEI ZHANG ${ }^{1}$, JINGRONG LIN $^{1}$ and ZHIQI SONG ${ }^{1}$ \\ ${ }^{1}$ Department of Dermatology, The First Affiliated Hospital of Dalian Medical University, Dalian, Liaoning 116011; \\ ${ }^{2}$ Institute of Cancer Stem Cell, Dalian Medical University, Dalian, Liaoning 116044, P.R. China
}

Received July 5, 2016; Accepted November 11, 2016

DOI: $10.3892 /$ or.2017.5450

\begin{abstract}
Malignant melanoma is the most invasive and fatal form of cutaneous cancer. Moreover it is extremely resistant to conventional chemotherapy and radiotherapy. Apigenin, a non-mutagenic flavonoid, has been found to exhibit chemopreventive and/or anticancerogenic properties in many different types of human cancer cells. Therefore, apigenin may have particular relevance for development as a chemotherapeutic agent for cancer treatment. In the present study, we investigated the effects of apigenin on the viability, migration and invasion potential, dendrite morphology, cell cycle distribution, apoptosis, phosphorylation of the extracellular signal-regulated protein kinase (ERK) and the AKT/mTOR signaling pathway in human melanoma A375 and C8161 cell lines in vitro. Apigenin effectively suppressed the proliferation of melanoma cells in vitro. Moreover, it inhibited cell migration and invasion, lengthened the dendrites, and induced $\mathrm{G}_{2} / \mathrm{M}$ phase arrest and apoptosis. Furthermore, apigenin promoted the activation of cleaved caspase- 3 and cleaved PARP proteins and decreased the expression of phosphorylated (p)-ERK1/2 proteins, $\mathrm{p}-\mathrm{AKT}$ and $\mathrm{p}-\mathrm{mTOR}$. Consequently, apigenin is a novel therapeutic candidate for melanoma.
\end{abstract}

\section{Introduction}

Malignant melanoma has recently been reported to have one of the highest incidence rates among all types of cancer, with an increasing number of melanoma-related deaths each year (1). The principal cause of death in melanoma patients is attributed to widespread metastases to the lymphatic

Correspondence to: Professor Zhiqi Song, Department of Dermatology, The First Affiliated Hospital of Dalian Medical University, 222 Zhongshan Road, Dalian, Liaoning 116011, P.R. China E-mail: szqdalian@163.com

\section{${ }^{*}$ Contributed equally}

Key words: apigenin, melanoma, apoptosis, proliferation, invasion, ERK pathway system and other organs (2). Following traditional therapy, the average survival time of patients with metastatic melanoma is only 6-12 months and the 5-year survival rate is consistently $<10 \%$ in most cases (3). However, tremendous progress in both immunotherapy and molecular-targeted therapy has revolutionized the standard of care for terminal melanoma patients. In the meantime, some new challenges for clinicians have also surfaced (4). One such example is molecular-targeted therapy which often leads to fast-acting and significant responses in most patients with the targeted mutation, while the clinical benefit is usually transient due to the rapid emergence of drug resistance. Consequently, it is urgent to develop efficient agents that may be applied for melanoma treatment.

Apigenin, a natural plant flavonoid (4',5,7-trihydroxyflavone), is widespread in common fruits and vegetables. According to the Biopharmaceutics Classification System, apigenin is categorized as a class II drug with poor solubility and high intestinal membrane permeability (5). The oral bioavailability of apigenin is relatively low due to its low solubility in water $(\sim 2.16 \mu \mathrm{g} / \mathrm{ml})(5)$ and in high hydrophilic or nonpolar solvents $(0.001-1.63 \mathrm{mg} / \mathrm{ml})(6)$, which has extremely hampered its clinical development. Several formulation strategies have been investigated to improve the bioavailability for application, including liposome (7) and nanocrystals fabricated by high pressure homogenization (8).

Apigenin has been shown to have marked anti-inflammatory, antioxidant and anticarcinogenic properties (9). Recently researchers have demonstrated that apigenin has an anti-proliferative effect on a variety of cancer cells, such as bladder, ovarian, breast and prostate cancer (10-15), including melanoma $(16,17)$. Apoptosis plays a critical role in controlling cell proliferation and thus is pivotal for the prevention of cancer progression and oncogenesis (18). Extracellular signalregulated kinase (ERK) is a crucial signaling molecule that regulates cell survival and proliferation. The ERK signaling pathway controls various pro- and anti-apoptotic mechanisms that determine cell viability (19). AKT serves as an antiapoptotic signaling molecule and inhibits apoptosis through mitochondrial pathways (20). Consequently, in the present study, we investigated the effects of apigenin on the viability, migration and invasion potential, dendrite morphology, cell cycle distribution, apoptosis, ERK expression and the AKT/mTOR signaling pathway. 


\section{Materials and methods}

Chemicals and reagents. Apigenin (no. A0113, CAS: 520-36-5, purity $\geq 98 \%$ ) was purchased from Chengdu Must Bio-Technology Co., Ltd. (Chengdu, China). Dulbecco's modified Eagle's medium (DMEM), trypsin and fetal bovine serum (FBS) were purchased from Gibco BRL (Grand Island, NY, USA). Dimethyl sulfoxide (DMSO), 3-(4,5-dimethylthiazol-2-yl)-2,5-diphenyltetrazolium bromide (MTT), Triton X-100 and anti- $\beta$-actin antibody were purchased from Sigma Chemical Co. (St. Louis, MO, USA). Trypsin free of ethylenediaminetetraacetic acid (EDTA) was purchased from Hyclone Co. (Logan, UT, USA). Matrigel was purchased from BD Biosciences (Franklin Lakes, NJ, USA). FITC-Annexin V kit was obtained from Nanjing KeyGen Biotech Co., Ltd. (Nanjing, China). Propidium iodide (PI) and RNase were purchased from Takara Bio, Inc. (Otsu, Shiga, Japan). Antibodies for ERK1/2 and phosphorylated (p)-ERK1/2 were purchased from Promega Corp. (Madison, WI, USA).The antibodies for poly(ADP-ribose) polymerase (PARP), caspase-3, AKT, p-AKT (Ser473), mTOR and p-mTOR (Ser2448) were purchased from Cell Signaling Technology Inc. (Beverly, MA, USA).

Cell culture and apigenin treatment. Human malignant melanoma A375 and C8161 cell lines were obtained from Peking Union Cell Resource Center (Beijing, China). The cells were grown at $37^{\circ} \mathrm{C}$ in a humidified atmosphere containing $5 \% \mathrm{CO}_{2}$. The cells were cultured and maintained in DMEM supplemented with $1 \%$ penicillin-streptomycin and 10\% FBS. A375 and C8161 cells were treated with different concentrations of apigenin (dissolved in DMSO) whereas the control cells were treated with an equivalent volume of DMSO.

MTT assays. For cell proliferation assays, the A375 and C8161 cells were seeded in 96-well plates at a concentration of $1 \times 10^{4}$ cells/well. Cells were allowed to adhere for $24 \mathrm{~h}$ and subsequently exposed to different concentrations of apigenin $(40,80,120,160,200,240$ and $280 \mu \mathrm{M})$ and incubated at $37^{\circ} \mathrm{C}$ for $24,48,72$ and $96 \mathrm{~h}$. MTT solution was added to each well at the specified time-point and incubated for an additional $4 \mathrm{~h}$. The culture medium in each well was discarded and replaced with DMSO to dissolve the formazan crystals which were formed from the MTT. The absorbance value was evaluated using an automatic microplate reader (T17108U; PerkinElmer, Inc., Waltham, MA, USA) at $490 \mathrm{~nm}$.

Cell migration assays in vitro. Cell migration was performed using the wound healing assay. A375 and C8161 cells were seeded in a 24 -well plate at a concentration of $5 \times 10^{5}$ cells/well and allowed to form a confluent monolayer for $24 \mathrm{~h}$. The monolayer was scratched with a sterile pipette tip $(10 \mu \mathrm{l})$ then washed with serum-free medium to remove the floating and detached cells. After treatment with 40 and $80 \mu \mathrm{M}$ of apigenin or DMSO, the cells were observed and photographed (time $0 \mathrm{~h}$ and $24 \mathrm{~h}$ ) using an inverted microscope (Olympus Corporation, Tokyo, Japan). Moreover, the number of cells migrating to the wound was assessed. Data were obtained from three independent experiments.
Cell invasion assay. Cell culture inserts (24-well, pore size $8 \mu \mathrm{m}$; BD Biosciences) were seeded with $1 \times 10^{6}$ cells $/ \mathrm{ml}$ in $100 \mu \mathrm{l}$ of serum-free medium with $40 \mu \mathrm{M}$ apigenin, or DMSO. Inserts were precoated with $10 \mu 1$ of Matrigel $(3 \mathrm{mg} / \mathrm{ml}$; Becton-Dickinson, Mountain View, CA, USA). Medium with $10 \%$ FBS $(500 \mu \mathrm{l})$ was added to the lower chamber and served as a chemotactic agent. After incubation for $72 \mathrm{~h}$, non-invasive cells were wiped from the upper surface of the membrane. Cells on the lower side were fixed with chilled methanol, stained with crystal violet (dissolved in methanol) and counted using an inverted microscope. Each individual experiment had triplicate inserts and five random, non-overlapping fields at a magnification of $x 200$ were counted per insert.

Scanning electron microscopy. A375 and C8161 cells were plated at a concentration of $2 \times 10^{4}$ cells/well into a $60-\mathrm{mm}$ culture dish. After treatment with $100 \mu \mathrm{M}$ of apigenin or DMSO for $24 \mathrm{~h}$, the cells were harvested, washed with PBS and fixed with $2.5 \%$ glutaraldehyde and $1 \%$ osmium tetraoxide, followed by an increasing gradient dehydration step using ethanol solutions of 50, 70, 95 and $100 \%$. Samples were sputter-coated with platinum and palladium before being observed under a scanning electron microscope (Quanta 200F; FEI, Hillsboro, OR, USA).

Cell apoptosis. Cells were placed in 6-well culture plates $\left(5 \times 10^{4}\right.$ cells $\left./ \mathrm{ml}\right)$ and allowed to attach for $8 \mathrm{~h}$. A375 and C8161 cells were treated with apigenin (40 and $100 \mu \mathrm{M}$, respectively) or DMSO for $24 \mathrm{~h}$. Following the manufacturer's instructions, the cells were harvested by trypsinization free of EDTA, washed in cold PBS and resuspended in binding buffer at a concentration of $1 \times 10^{6}$ cells $/ \mathrm{ml}$. FITC-conjugated Annexin V (BioVision, Inc., Milpitas, CA, USA) and PI (5 $\mu 1$ each) (Becton-Dickinson) were added to the cells, gently mixed and then incubated for $15 \mathrm{~min}$ at room temperature in the dark. Afterwards binding buffer was added and the cells were analyzed by flow cytometry.

Cell cycle analysis. Cells were seeded in $60-\mathrm{mm}$ culture dishes. After attachment, the cells were treated with $100 \mu \mathrm{M}$ apigenin or DMSO for $24 \mathrm{~h}$. Then cells were harvested and fixed with ice-cold $75 \%$ ethanol. The cell pellets were resuspended in binding buffer consisting of $480 \mu 1$ PBS, $5 \mu \mathrm{l} \mathrm{PI}(5 \mathrm{mg} / \mathrm{ml}), 5 \mu \mathrm{l} \mathrm{RNase}(10 \mathrm{mg} / \mathrm{ml})$ and $10 \mu \mathrm{l}$ Triton X-100 (10\%). After $30 \mathrm{~min}$ of incubation at room temperature in the dark, the DNA content of the cells was examined using a flow cytometer (Accuri C6; Becton-Dickinson) for cell cycle phase distribution.

Western blot analysis. Cells were plated in 6-well culture plates at concentrations determined to yield $60-70 \%$ confluence within $24 \mathrm{~h}$. Next, the cells were left untreated or treated with $100 \mu \mathrm{M}$ apigenin for $24 \mathrm{~h}$. After preparing appropriate protein concentrations of $25 \mu \mathrm{g}$, sodium dodecyl sulfate-polyacrylamide gel electrophoresis (SDS-PAGE) was performed. Proteins were separated by electrophoresis and transferred onto nitrocellulose membranes and afterwards blocked for $1 \mathrm{~h}$ with $5 \%$ non-fat dry milk in TBS-T. The membranes were incubated with respective primary antibodies at appropriate concentrations overnight at $4^{\circ} \mathrm{C}$. After being washed to remove 
unbound primary antibodies, they were incubated with the corresponding secondary antibodies. Proteins were visualized by image scanning and the optical density for each band was assessed using Image Lab software (version 4.0; Bio-Rad, Hercules, CA, USA) after data were normalized to $\beta$-actin as an internal reference.

Statistical analysis. All the experiments were carried out in triplicate and the values are expressed as the mean \pm standard deviation (SD). SPSS v17.0 software (SPSS, Inc., Chicago, IL, USA) was used for statistical analysis. The repeated experiments used analysis of variance, Dunnett's test and Student's t-test for the assessment of differences between groups. A probability value of $\leq 0.05$ was deemed statistically significant. ${ }^{*} \mathrm{P}<0.05,{ }^{* *} \mathrm{P}<0.01$ and ${ }^{* * *} \mathrm{P}<0.001$ as indicated in the figures, are relative to the controls.

\section{Results}

Apigenin inhibits A375 and C8161 cell proliferation. To investigate the growth inhibitory effect of apigenin, A375 and C8161 cells were treated with different concentrations $(40,80$, $120,160,200,240$ and $280 \mu \mathrm{M}$ ) of apigenin for different periods of time $(24,48,72$ and $96 \mathrm{~h})$. The cell viability was assessed by MTT assay. As shown in Fig. 1, cell growth inhibition caused by apigenin was relatively marked in a dose-dependent, as well as a time-dependent manner (ranging from 40-160 $\mu \mathrm{M}$ within $48 \mathrm{~h}$ ). The $\mathrm{IC}_{50}$ value at $24 \mathrm{~h}$ was estimated to be $100 \mu \mathrm{M}$.

Apigenin inhibits A375 and C8161 cell migration potential. To assess whether or not apigenin has an effect on the metastasis of A375 and C8161 cell lines, we examined the number of migratory cells using a wound-healing approach. Migration was significantly inhibited in the A375 and C8161 cell lines after treatment with apigenin $(40$ and $80 \mu \mathrm{M})$ for $24 \mathrm{~h}$ $(\mathrm{P}<0.001)$ (Fig. 2). When the cells were exposed to $100 \mu \mathrm{M}$ of apigenin for $24 \mathrm{~h}$, no migrating cells were observed (data not shown).

Apigenin suppresses the invasion of A375 and C8161 cells. We further investigated cell motility by invasion assays. Both the density of the invasive cells on the membrane and the number of invasive cells/field are shown in Fig. 3. Treatment with $40 \mu \mathrm{M}$ of apigenin for $72 \mathrm{~h}$ significantly decreased the invasive ability of the A375 and C8161 melanoma cells compared with the control cells $(\mathrm{P}<0.001)$. Following treatment with $80 \mu \mathrm{M}$ of apigenin, no invading cells were observed (data not shown). These findings demonstrated that apigenin decreased the invasion of melanoma cells in vitro.

Apigenin affects the dendrite morphology of A375 and C8161 cells. Following treatment with $100 \mu \mathrm{M}$ of apigenin for $24 \mathrm{~h}$, both the A375 and C8161 cells changed their cellular morphology as visualized using scanning electron microscopy. The dendrites became thinner and longer compared to those noted in the untreated control cells $(\mathrm{P}<0.001)$ (Fig. 4).

Apigenin promotes the apoptosis of A375 and C8161 cells. To ascertain the underlying mechanism which leads to apigenin-induced inhibition of cell proliferation, we observed
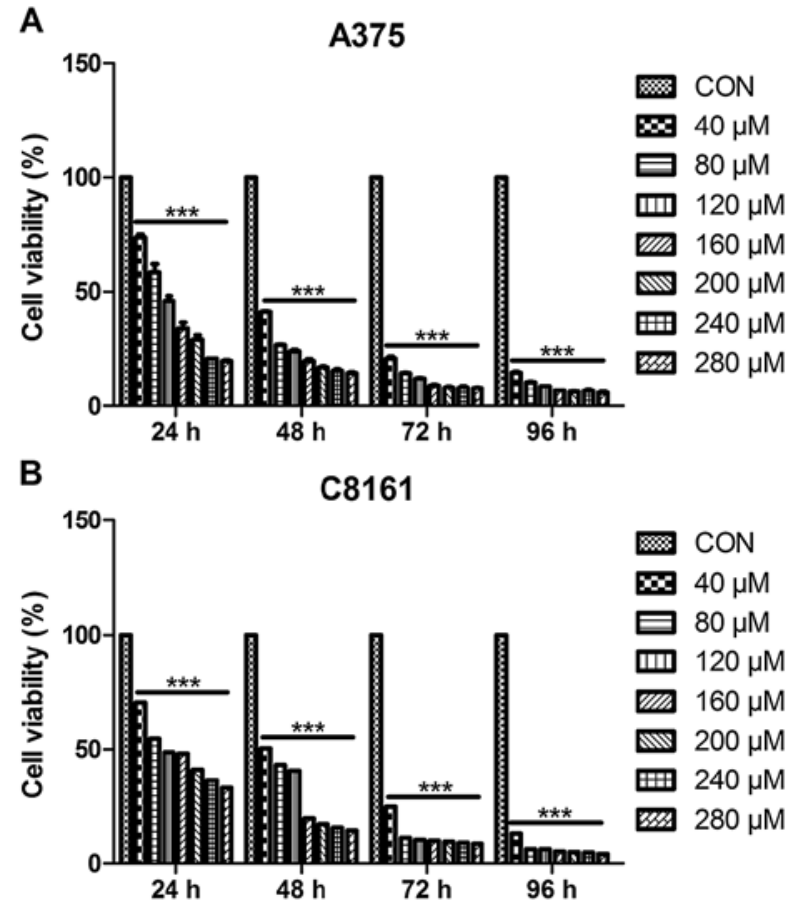

Figure 1. Effect of apigenin on A375 and C8161 cell proliferation. Cell survival was determined by the MTT assay. (A) A375 cell growth was inhibited in a dose-dependent and a time-dependent manner after apigenin exposure. (B) Dose-dependent and time-dependent response in C8161 cells after apigenin treatment at 24, 48, 72 and $96 \mathrm{~h}$. Data are presented as the mean $\pm \mathrm{SD}$ from at least triplicate wells and of three separate experiments. ${ }^{* * *} \mathrm{P}<0.001$ vs. control.
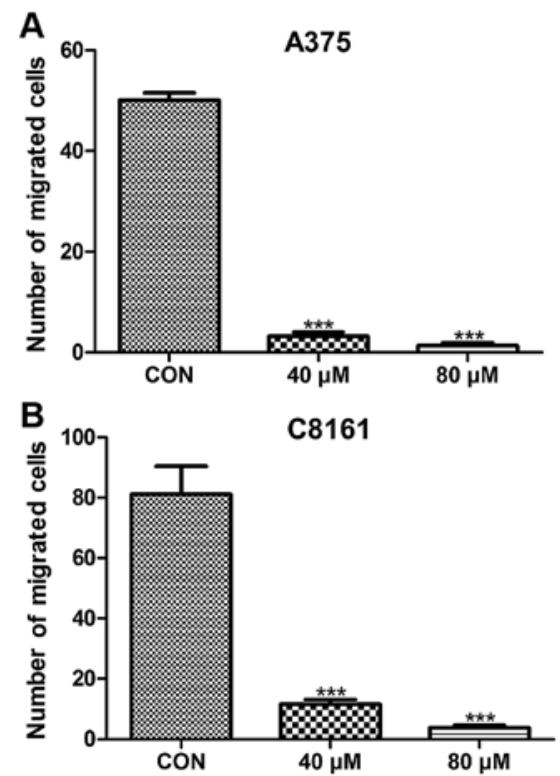

Figure 2. Effect of apigenin treatment on the migratory behavior of A375 and C8161 cells. Apigenin inhibited the migration of A375 and C8161 cells. (A) Quantification of the wound-healing assay of A375 cells after apigenin (40 and $80 \mu \mathrm{M}$ ) treatment for $24 \mathrm{~h}$. (B) Quantification of the wound-healing assay of C8161 cells after apigenin ( 40 and $80 \mu \mathrm{M})$ treatment for $24 \mathrm{~h}$. Data are presented as the mean \pm SD from at least triplicate wells and of three separate experiments. ${ }^{* * *} \mathrm{P}<0.001$ vs. control.

the effects of apigenin on the A375 and C8161 cells by detecting their apoptotic rates. Significant apoptosis was found in both the A375 and C8161 cell lines. Treatment with apigenin 

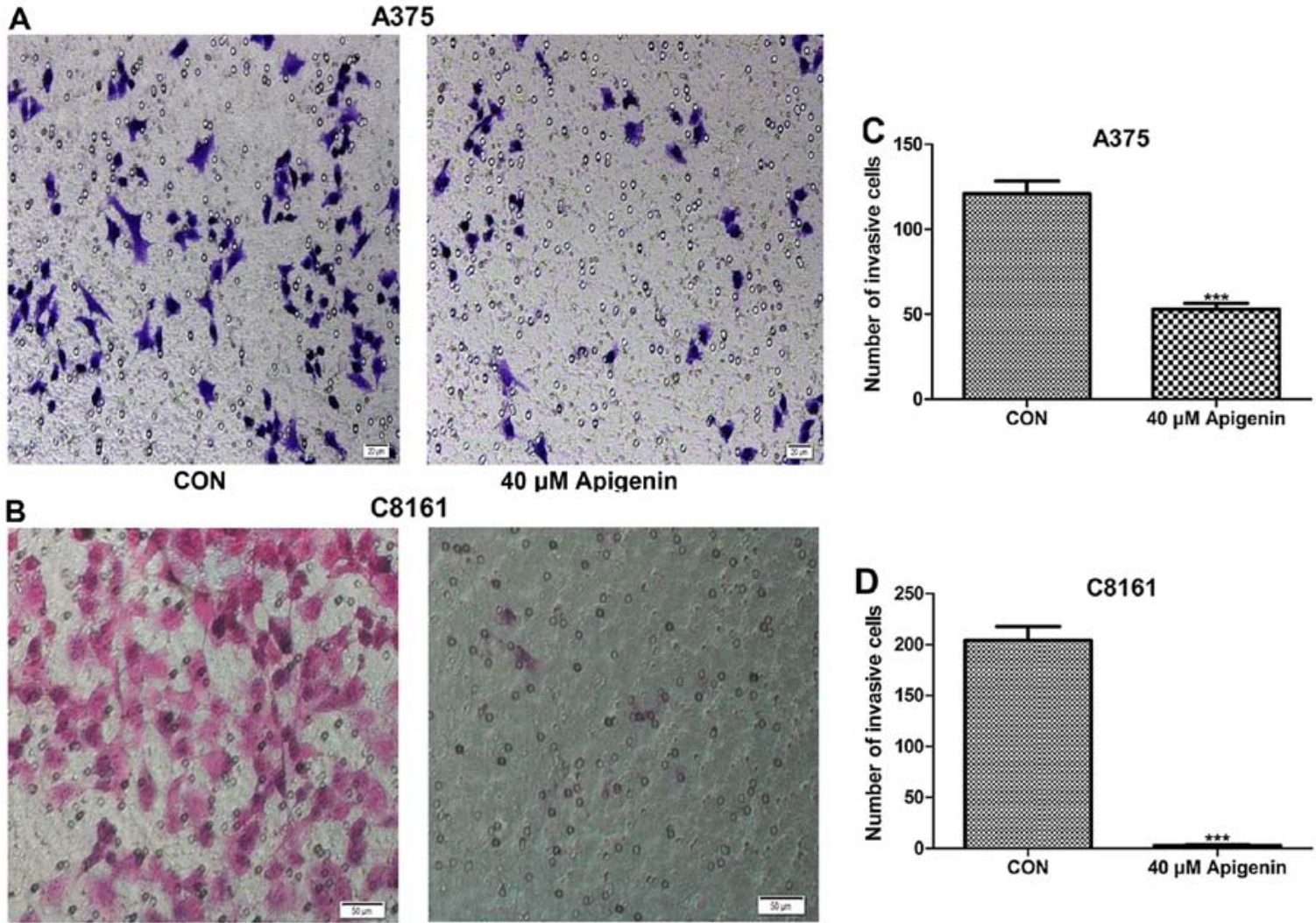

C8161

$40 \mu \mathrm{M}$ Apigenin
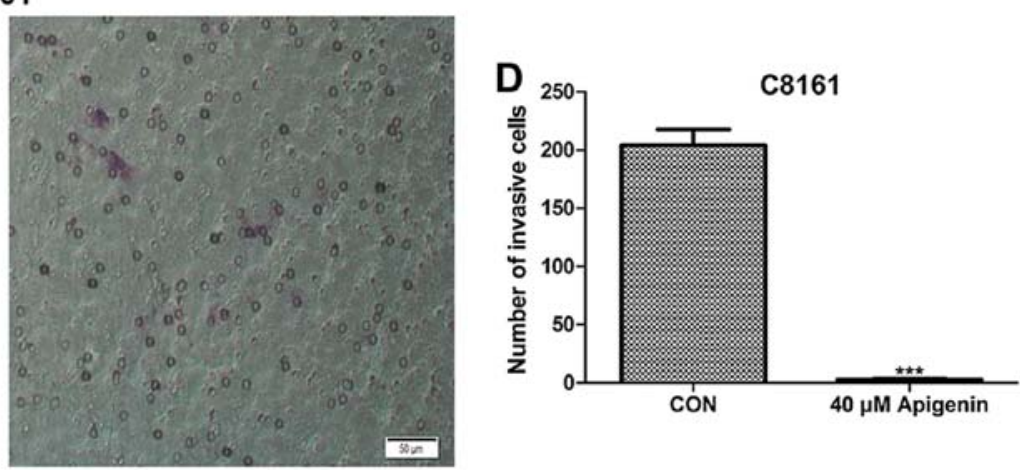

CON

$40 \mu \mathrm{M}$ Apigenin

Figure 3. Effect of apigenin treatment on the invasive ability of A375 and C8161 cells. The invasive capacity was assessed by employing a Transwell chamber assay. (A and B) Representative photomicrographs of the inhibition of cell invasion following treatment with $40 \mu \mathrm{M}$ of apigenin (crystal violet staining, magnification, x200; representative image from three independent experiments). (C and D) Histograms of the number of invasive cells after treatment with $40 \mu \mathrm{M}$ of apigenin. Data are presented as the mean $\pm \mathrm{SD}$ from at least triplicate wells and of three separate experiments. ${ }^{* * *} \mathrm{P}<0.001 \mathrm{vs}$. control.

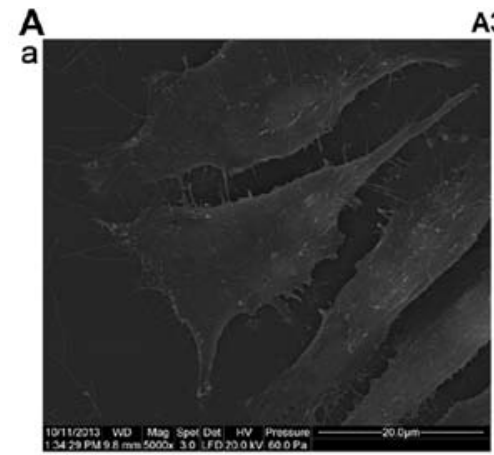

A375

B
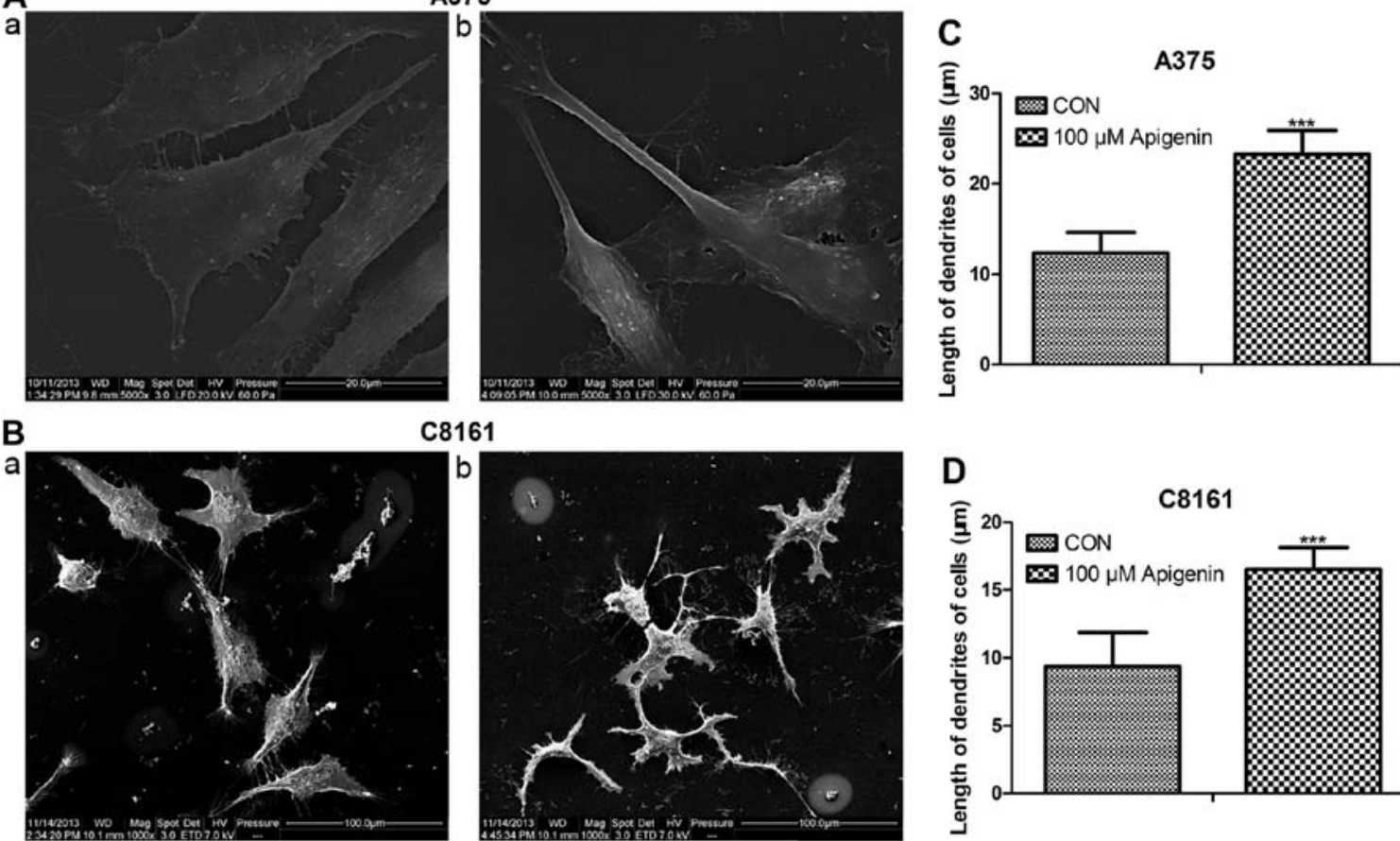

C8161
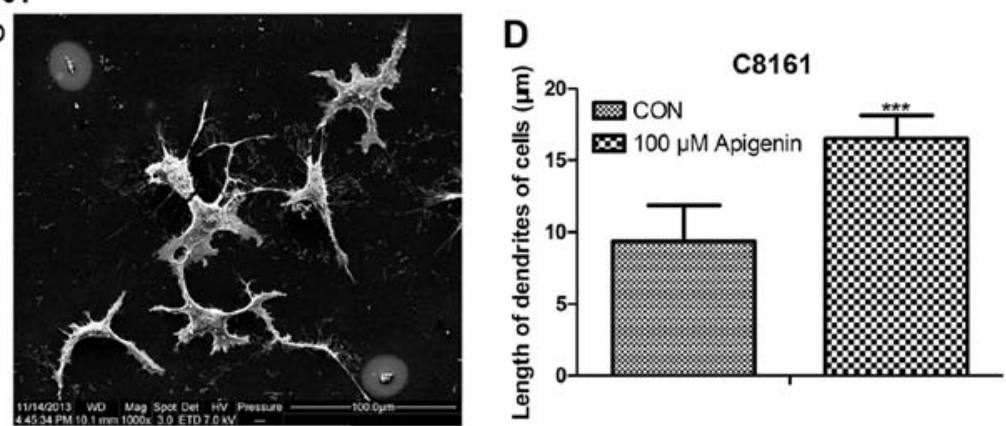

Figure 4. Morphological alteration is induced in A375 and C8161 cells by apigenin. Cells were treated with apigenin (100 $\mu \mathrm{M})$ for $24 \mathrm{~h}$ and then observed by scanning electron microscopy. (A) Dendrites became thinner and longer in the A375 cells compared to the control group. a, DMSO control group; b, A375 cells. (B) Dendrites became thinner and longer in the C8161 cells compared to the control group. a, DMSO control group; b, C8161 cells. (C and D) Quantification of the dendrite length of A375 and C8161 cells after apigenin treatment. Data are presented as the mean \pm SD from at least triplicate wells and of three separate experiments. ${ }^{* * * *} \mathrm{P}<0.001$ vs. control. DMSO, dimethyl sulfoxide. 
A

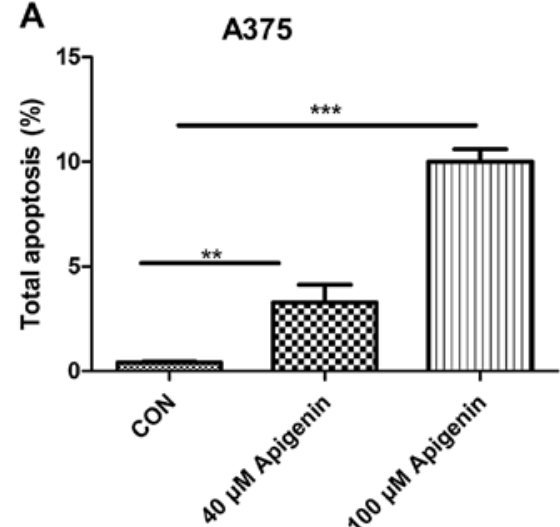

B

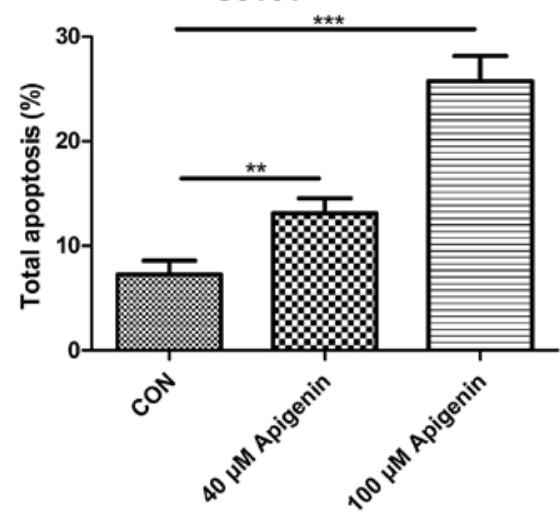

Figure 5. Induction of apoptosis in A375 and C8161 cells by apigenin. Cells were treated with apigenin ( 40 and $100 \mu \mathrm{M}$ ) for $24 \mathrm{~h}$ and then the rates of apoptosis were determined by FITC-Annexin V/PI assay kit. (A) Quantification of the apoptosis rate of A375 cells after apigenin treatment. (B) Quantification of the apoptosis rate of C8161 cells after apigenin treatment. Data are presented as the mean \pm SD from at least triplicate wells and of three separate experiments. ${ }^{* *} \mathrm{P}<0.01$ vs. control. ${ }^{* * * *} \mathrm{P}<0.001$ vs. control.

(40 and $100 \mu \mathrm{M}$ ) for $24 \mathrm{~h}$, resulted in higher apoptosis rates of the A375 and C8161 cells than the rates noted in the untreated control cells, and the effects occurred in a dose-dependent manner $(\mathrm{P}<0.01, \mathrm{P}<0.001)$ (Fig. 5).

Apigenin arrests $A 375$ and $C 8161$ cells at the $G_{2} / M$ phase of the cell cycle. Cell cycle analysis was also performed by flow cytometry. A375 and C8161 cells were treated with $100 \mu \mathrm{M}$ of apigenin for $24 \mathrm{~h}$. As shown in Fig. 6, apigenin treatment resulted in a noticeable accumulation of cells in the $\mathrm{G}_{2} / \mathrm{M}$ phase with a decrease in the $\mathrm{G}_{0} / \mathrm{G}_{1}$ phase during the cell cycle $(\mathrm{P}<0.05, \mathrm{P}<0.01, \mathrm{P}<0.001)$. This blockage of cell progression may be one of the mechanisms by which apigenin exerts its anti-proliferative effect on melanoma cell lines.

Apigenin alters ERK protein expression. Western blot analysis showed that treatment with $100 \mu \mathrm{M}$ of apigenin significantly increased the expression of cleaved caspase- 3 and cleaved PARP in the A375 and C8161 cells, while it decreased the expression of p-ERK1/2 but did not alter the total ERK1/2 level as compared to the DMSO controls $(\mathrm{P}<0.05, \mathrm{P}<0.01$, $\mathrm{P}<0.001$ ) (Fig. 7).

Apigenin inhibits the AKT signaling pathway. Western blot analysis revealed that the expression levels of phosphorylated
A
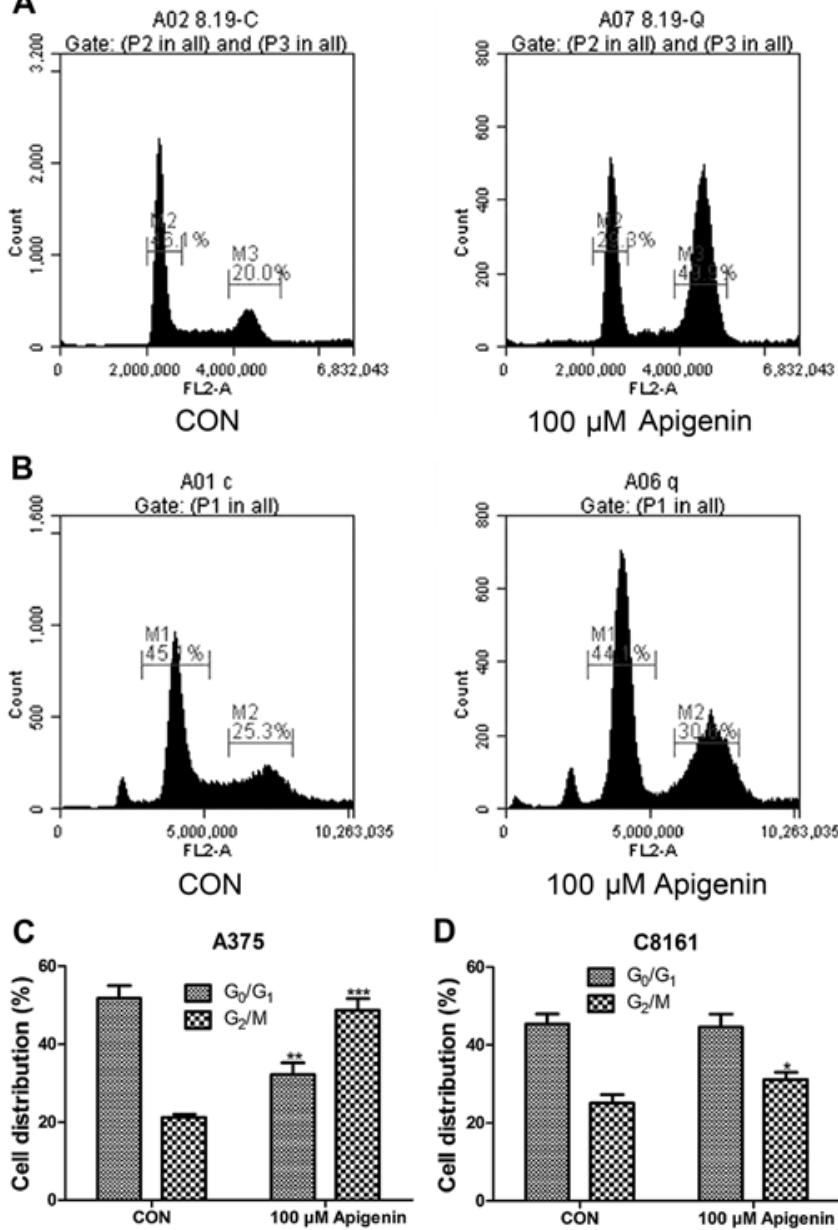

$100 \mu \mathrm{M}$ Apigenin

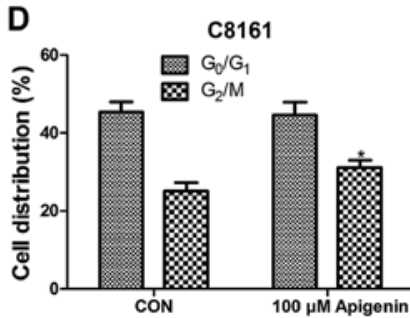

Figure 6. Induction of $\mathrm{G}_{2} / \mathrm{M}$ phase arrest in the A375 and C8161 cells by apigenin. Cell cycle distribution was analyzed at $24 \mathrm{~h}$ after treatment with DMSO (vehicle control) or $100 \mu \mathrm{M}$ of apigenin. (A and C) Apigenin increased the percentage of $\mathrm{A} 375$ cells in $\mathrm{G}_{2} / \mathrm{M}$ phase arrest from 21.30 to $48.70 \%$ while it decreased the percentage in the $\mathrm{G}_{0} / \mathrm{G}_{1}$ phase from 51.80 to $32.30 \%$. (B and D) Apigenin increased the percentage of C8161 cells in $G_{2} / M$ phase arrest from 25.06 to $31.10 \%$ while it decreased the percentage in the $\mathrm{G}_{0} / \mathrm{G}_{1}$ phase from 45.37 to $44.63 \%$. Data are presented as the mean \pm SD from at least triplicate wells and of three separate experiments. ${ }^{*} \mathrm{P}<0.05$ vs. control. ${ }^{* *} \mathrm{P}<0.01$ vs. control. ${ }^{* * *} \mathrm{P}<0.001$ vs. control. DMSO, dimethyl sulfoxide.

AKT (p-AKT) and p-mTOR were decreased after treatment with $100 \mu \mathrm{M}$ of apigenin, whereas no significant difference was observed in total AKT and mTOR, in comparison to the DMSO controls $(\mathrm{P}<0.001)$ (Fig. 8).

\section{Discussion}

Melanoma is one of the most malignant cancers with a propensity for metastases. The well-established conventional treatments for melanoma, such as cryotherapy, surgery, and chemotherapy (21) and some nonsurgical treatments are usually limited to adjuvant therapies. Therefore, increasing interest has focused on the search for natural dietary phytochemicals both safe and effective against melanoma. It is generally known that many compounds from natural plants possess chemopreventative and chemotherapeutic efficacy in human cancers including melanoma (22). Apigenin, a flavonoid belonging to the flavone subgroup, is present in various vegetables, herbs, fruits and Chinese traditional 
A

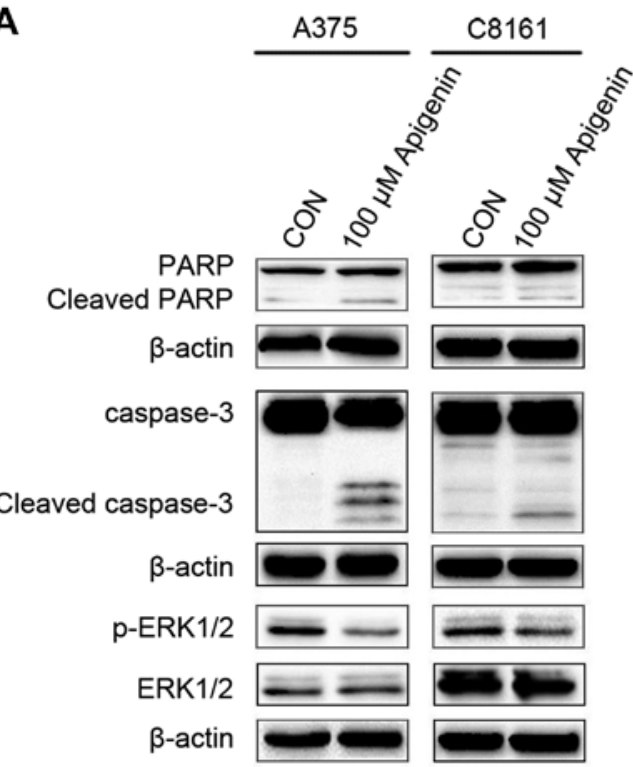

B

A375

C8161
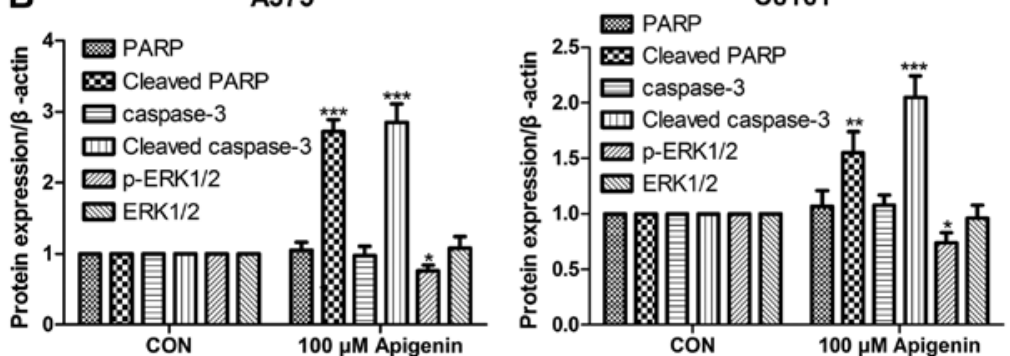

Figure 7. Inhibition of ERK phosphorylation following apigenin treatment in A375 and C8161 cells. A375 and C8161 cells were incubated with DMSO or $100 \mu \mathrm{M}$ of apigenin for $24 \mathrm{~h}$. (A) Investigated proteins were analyzed by western blot analysis. (B) Relative amounts of the investigated proteins expressed in A375 and C8161 cells. The expression of cleaved caspase-3 and cleaved PARP was increased while the content of p-ERK1/2 decreased and the total ERK1/2 level was invariant. Data are presented as the mean \pm SD from at least triplicate wells and of three separate experiments. " $\mathrm{P}<0.05$ vs. control. ${ }^{* *} \mathrm{P}<0.01$ vs. control. ${ }^{* * *} \mathrm{P}<0.001$ vs. control. DMSO, dimethyl sulfoxide.

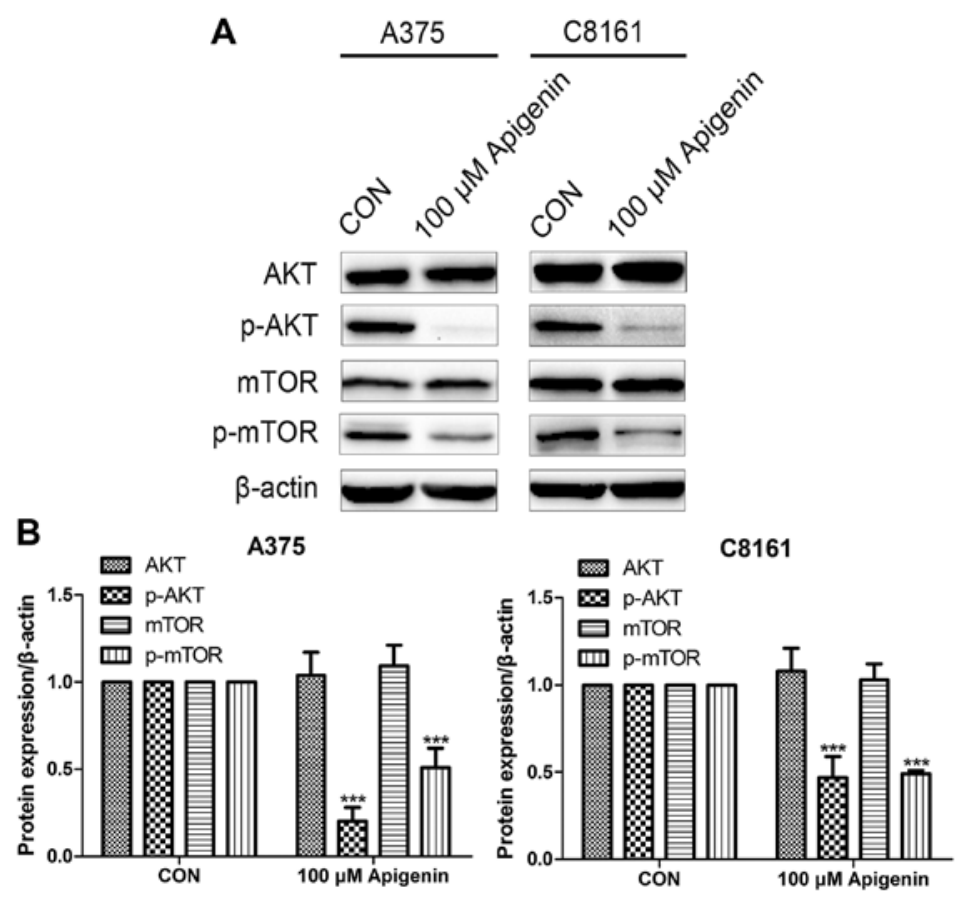

Figure 8. AKT signaling pathway is inhibited in A375 and C8161 cells treated with $100 \mu \mathrm{M}$ of apigenin for $24 \mathrm{~h}$. (A) Apigenin significantly decreased the expression of phosphorylated (p)-AKT and p-mTOR, but the expression of total AKT and mTOR was not altered. (B) Relative amounts of the investigated proteins expressed in the A375 and C8161 cells. Data are presented as the mean \pm SD from at least triplicate wells and of three separate experiments. ${ }^{* * *} \mathrm{P}<0.001$ vs. control. 
medications $(9,23)$ and has been shown to suppress tumor growth through inhibition of cell proliferation (24).

In the present study, we investigated the chemotherapeutic capacity of apigenin against human melanoma. We selected the human melanoma A375 and C8161 cell lines which have a different BRAF mutation status. A375 cells harbor the BRAF $^{V 600 E}$ mutation while C8161 cells contain the BRAF wild-type gene. Apigenin, as shown in this study, significantly suppressed the growth of A375 and C8161 cells. These data suggest that apigenin possesses chemotherapeutic potential against human melanoma.

Dysregulation of the cell cycle is a hallmark of tumorigenesis. The cell cycle is controlled at multiple checkpoints. The $\mathrm{G}_{2} / \mathrm{M}$ checkpoint inhibits cells from entering mitosis when DNA is impaired, enabling cell repair. Pathways that result in apoptosis may be activated when the damage is irreparable (25). The $\mathrm{G}_{2} / \mathrm{M}$ checkpoint is controlled by $\mathrm{Cdc} 2 /$ cyclin $\mathrm{B}$, as well as their negative regulators including p21 ${ }^{\text {Cip1 }}$ and p27 (26). Regulating these $\mathrm{G}_{2} / \mathrm{M}$ checkpoint proteins may enhance the sensitivity of cancer cells to radiotherapy and chemotherapy (27). Therefore, the $\mathrm{G}_{2} / \mathrm{M}$ checkpoint is a potential target for cancer therapy. It has been reported that apigenin arrested human colon cancer HCT116 cells in the $\mathrm{G}_{2} / \mathrm{M}$ phase. Moreover, it suppressed the expression of both cyclin B1 and its activating partners, $\mathrm{Cdc} 2$ and $\mathrm{Cdc} 25 \mathrm{c}$ (28). In addition, apigenin treatment led to a significant accumulation of cells in the $\mathrm{G}_{2} / \mathrm{M}$ phase via the downregulation of $\mathrm{Cdc} 25 \mathrm{c}$ expression in human papillary thyroid carcinoma BCPAP cells (29). We found that apigenin suppressed the growth of human melanoma A375 and C8161 cells by inducing $G_{2} / M$ phase arrest of the cell cycle. Furthermore, apigenin treatment decreased the expression of $\mathrm{p}-\mathrm{AKT}$ and $\mathrm{p}-\mathrm{mTOR}$. Previous studies have indicated that the AKT/mTOR pathway could influence the progression of $\mathrm{G}_{2}$ to the mitosis phase through the regulation of the expression of $\mathrm{G}_{2} / \mathrm{M}$-related proteins (30). Expression of the active form of AKT increases Cdk1 both at the protein and mRNA level, while its predominant negative mutation suppresses cell proliferation by inducing $\mathrm{G}_{2} / \mathrm{M}$ arrest (31). Consequently, apigenin may inhibit proliferation of A375 and C8161 cells by arresting $\mathrm{G}_{2} / \mathrm{M}$ transition in the cell cycle probably via the AKT/mTOR pathway.

Invasion and metastasis are major concerns in the prognosis and progression of cancer. The AKT/mTOR pathway is pivotal in modulating the invasion and migration of tumor cells (32). This pathway promotes resistance to chemotherapy-induced apoptosis in a variety of cancers including melanoma (33). We found that $40 \mu \mathrm{M}$ of apigenin significantly inhibited cell migration and invasion. Furthermore, western blot analysis demonstrated that the expression levels of p-AKT and p-mTOR were decreased after apigenin treatment, while no significant difference was observed in total AKT and mTOR. These results indicate that the AKT/mTOR pathway plays an important role in the apigenin-induced inhibition of migration and invasion of A375 and C8161 cells. Erdogan et al (34) also showed that apigenin reduced prostate cancer $\mathrm{CD} 44^{+}$stem cell survival and migration through $\mathrm{PI} 3 \mathrm{~K} / \mathrm{AKT} / \mathrm{NF}-\kappa \mathrm{B}$ signaling.

Apoptosis, a type of programmed cell death, is a physiological process essential for normal tissue development (35). In mammals, there are two primary apoptotic pathways: the extrinsic pathway (death receptor-mediated pathway) and the intrinsic pathway (mitochondrial-mediated pathway) (36). Caspase- 3 is a key executioner caspase and its activation leads to the cleavage of PARP during cell death (37). Cleavage of PARP is regarded as a central indicator of apoptosis. The ERK and AKT signaling pathways are related to cell biological functions and cancer malignancies which could also play an important role in the proliferation and apoptosis of cancers. In our study, we confirmed that apigenin treatment resulted in higher apoptosis rates of the A375 and C8161 cells compared to the control cells in a dose-dependent manner and significantly increased the expression of cleaved caspase- 3 and cleaved PARP, while it decreased the expression of p-ERK1/2. The cell death occurring in the A375 and C8161 cells treated with apigenin was probably induced by apoptosis, which was possibly involved with ERK phosphorylation. Pretreatment of A375 and C8161 cells with ERK inhibitors is necessary to reveal whether apigenin-induced apoptosis is dependent on ERK activity and we will investigate the relevant mechanism in future research. Seo et al demonstrated that apigenin induced apoptosis via the extrinsic pathway, increasing p53 and inhibiting STAT3 and NF- $\mathrm{BB}$ signaling in HER2-overexpressing breast cancer cells (38). Shukla et al observed that apigenin induced apoptosis by targeting inhibitor of apoptosis proteins and $\mathrm{Ku} 70-\mathrm{Bax}$ interaction in prostate cancer (39). Das et al (40) found that apigenin induced apoptosis in A375 and A549 cells through selective action and dysfunction of mitochondria, suggesting the activation of the intrinsic apoptosis pathway. However, we did not ascertain whether apigenin induced cell apoptosis through the intrinsic or extrinsic pathway and this relevant research will be carried out in the future. In addition, our western blot analysis showed that the expression of p-AKT and p-mTOR was decreased after apigenin treatment, while the expression of total AKT and mTOR was not altered. This indicates that the AKT/mTOR pathway plays a vital role in the apigenin-induced apoptosis observed in A375 and C8161 cells. Zhu et al (30) demonstrated that apigenin induced apoptosis via the PI3K/AKT pathway, the regulation of the Bcl-2 family and activation of caspase-3 and PARP.

Recent studies have implicated glutamate signaling in the development of melanoma (41-43). The antagonists of ionotropic glutamate receptors (iGluRs) have been demonstrated to cause a rapid and reversible change in melanocyte morphology. Metabotropic glutamate 1 (mGlu1) receptor has been proposed as a target for metastatic melanoma therapy (44). It is expressed aberrantly in over half of human melanoma cell lines and biopsies (45). In our previous study (46), we found that the antagonists mGlul receptor and N-methyl-Daspartate (NMDA) receptor increased dendritic branching and inhibited the motility, migration and proliferation of the human metastatic melanoma cell line WM451. We also demonstrated that the invasion and motility effects were significantly inhibited by the combination of increased microtubule-associated protein (MAP)2a (MAP2a) expression and either an mGlu1 receptor or NMDA receptor antagonist. One plausible explanation for this phenomenon is that the blockade of the glutamate-mediated signaling pathway via the ERK1/2 pathway suppresses cell motility and invasion through a tubulin-dependent mechanism (47). In the present study, we found that the main cytodendrites of human melanoma A375 and C8161 cells following treatment with apigenin became 
thinner and longer than those of the controls. Moreover, treatment with apigenin significantly suppressed cell invasion and migration. We deduced that the aforementioned effects of apigenin may be induced by blocking the glutamatemediated signaling pathway, leading to cytoskeletal protein reorganization and tumor cell differentiation. These results suggest that the blockade of glutamate signaling is a promising novel therapy for the treatment of melanoma.

In conclusion, apigenin is a potent suppressor of cell viability, migration and invasion. Concomitantly, it induces apoptosis in human melanoma A375 and C8161 cells, via activation of caspase- 3 and PARP, inhibition of ERK phosphorylation and the AKT/mTOR pathway. Furthermore, it affects the dendrite morphology of the A375 and C8161 cells, which might be involved with the blockade of the glutamate signaling pathway. These findings need to be supported by further experimental evidence. Consequently, apigenin exhibits effective antineoplastic potency and provides a hopeful treatment paradigm for melanoma.

\section{Acknowledgements}

We would like to thank Quentin Liu for guidance in our study. The present study was supported by grants from the National Natural Science Foundation of China (nos. 81472865 and 81171491) and the Natural Science Foundation of Liaoning Province (no. 201102056).

\section{References}

1. Liu J, Gu J, Feng Z, Yang Y, Zhu N, Lu W and Qi F: Both HDAC5 and HDAC6 are required for the proliferation and metastasis of melanoma cells. J Transl Med 14: 7, 2016.

2. Agarwala SS: Current systemic therapy for metastatic melanoma. Expert Rev Anticancer Ther 9: 587-595, 2009.

3. Balch CM, Gershenwald JE, Soong SJ, Thompson JF, Atkins MB, Byrd DR, Buzaid AC, Cochran AJ, Coit DG, Ding S, et al: Final version of 2009 AJCC Melanoma Staging and Classification. J Clin Oncol 27: 6199-6206, 2009.

4. Zhu Z, Liu W and Gotlieb V: The rapidly evolving therapies for advanced melanoma - Towards immunotherapy, molecular targeted therapy, and beyond. Crit Rev Oncol Hematol 99: 91-99, 2015.

5. Zhang J, Liu D, Huang Y, Gao Y and Qian S: Biopharmaceutics classification and intestinal absorption study of apigenin. Int $\mathrm{J}$ Pharm 436: 311-317, 2012.

6. Ding SM, Zhang ZH, Song J, Cheng XD, Jiang J and Jia XB: Enhanced bioavailability of apigenin via preparation of a carbon nanopowder solid dispersion. Int J Nanomedicine 9: 2327-2333, 2014.

7. Arsić I, Tadić V, Vlaović D, Homšek I, Vesić S, Isailović G and Vuleta G: Preparation of novel apigenin-enriched, liposomal and non-liposomal, antiinflammatory topical formulations as substitutes for corticosteroid therapy. Phytother Res 25: 228-233, 2011.

8. Al Shaal L, Shegokar R and Müller RH: Production and characterization of antioxidant apigenin nanocrystals as a novel UV skin protective formulation. Int J Pharm 420: 133-140, 2011.

9. Patel D, Shukla S and Gupta S: Apigenin and cancer chemoprevention: Progress, potential and promise (Review). Int J Oncol 30: 233-245, 2007.

10. Shi MD, Shiao CK, Lee YC and Shih YW: Apigenin, a dietary flavonoid, inhibits proliferation of human bladder cancer T-24 cells via blocking cell cycle progression and inducing apoptosis. Cancer Cell Int 15: 33, 2015.

11. Suh YA, Jo SY, Lee HY and Lee C: Inhibition of IL-6/STAT3 axis and targeting Axl and Tyro3 receptor tyrosine kinases by apigenin circumvent taxol resistance in ovarian cancer cells. Int J Oncol 46: 1405-1411, 2015.
12. Shukla S, Bhaskaran N, Babcook MA, Fu P, Maclennan GT and Gupta S: Apigenin inhibits prostate cancer progression in TRAMP mice via targeting PI3K/Akt/FoxO pathway. Carcinogenesis 35: 452-460, 2014.

13. Shukla S, Kanwal R, Shankar E, Datt M, Chance MR, Fu P, MacLennan GT and Gupta S: Apigenin blocks IKK $\alpha$ activation and suppresses prostate cancer progression. Oncotarget 6: 31216-31232, 2015.

14. Scherbakov AM and Andreeva OE: Apigenin inhibits growth of breast cancer cells: The role of ER $\alpha$ and HER2/neu. Acta naturae 7: 133-139, 2015.

15. Seo HS, Ku JM, Choi HS, Woo JK, Jang BH, Go H, Shin YC and Ko SG: Apigenin induces caspase-dependent apoptosis by inhibiting signal transducer and activator of transcription 3 signaling in HER2-overexpressing SKBR3 breast cancer cells. Mol Med Rep 12: 2977-2984, 2015.

16. Caltagirone S, Rossi C, Poggi A, Ranelletti FO, Natali PG, Brunetti M, Aiello FB and Piantelli M: Flavonoids apigenin and quercetin inhibit melanoma growth and metastatic potential. Int J Cancer 87: 595-600, 2000.

17. Ye Y, Chou GX, Wang H, Chu JH and Yu ZL: Flavonoids, apigenin and icariin exert potent melanogenic activities in murine B16 melanoma cells. Phytomedicine 18: 32-35, 2010.

18. Ghobrial IM, Witzig TE and Adjei AA: Targeting apoptosis pathways in cancer therapy. CA Cancer J Clin 55: 178-194, 2005.

19. Pang W, Leng X, Lu H, Yang H, Song N, Tan L, Jiang Y and Guo C: Depletion of intracellular zinc induces apoptosis of cultured hippocampal neurons through suppression of ERK signaling pathway and activation of caspase-3. Neurosci Lett 552: 140-145, 2013.

20. Chan TO, Rittenhouse SE and Tsichlis PN: AKT/PKB and other D3 phosphoinositide-regulated kinases: Kinase activation by phosphoinositide-dependent phosphorylation. Annu Rev Biochem 68: 965-1014, 1999.

21. Lopez RF, Lange N, Guy R and Bentley MV: Photodynamic therapy of skin cancer: Controlled drug delivery of 5-ALA and its esters. Adv Drug Deliv Rev 56: 77-94, 2004.

22. Eggler AL, Gay KA and Mesecar AD: Molecular mechanisms of natural products in chemoprevention: Induction of cytoprotective enzymes by Nrf2. Mol Nutr Food Res 52 (Suppl 1): S84-S94, 2008.

23. Shukla S and Gupta S: Apigenin: A promising molecule for cancer prevention. Pharm Res 27: 962-978, 2010.

24. Kim MA, Kang K, Lee HJ, Kim M, Kim CY and Nho CW: Apigenin isolated from Daphne genkwa Siebold et Zucc. inhibits 3T3-L1 preadipocyte differentiation through a modulation of mitotic clonal expansion. Life Sci 101: 64-72, 2014.

25. Wang Y, Ji P, Liu J, Broaddus RR, Xue F and Zhang W: Centrosome-associated regulators of the $\mathrm{G}_{2} / \mathrm{M}$ checkpoint as targets for cancer therapy. Mol Cancer 8: 8, 2009.

26. Dash BC and El-Deiry WS: Phosphorylation of $\mathrm{p} 21$ in $\mathrm{G}_{2} / \mathrm{M}$ promotes cyclin B-Cdc2 kinase activity. Mol Cell Biol 25: 3364-3387, 2005.

27. Stewart ZA, Westfall MD and Pietenpol JA: Cell-cycle dysregulation and anticancer therapy. Trends Pharmacol Sci 24: 139-145, 2003.

28. Lee Y, Sung B, Kang YJ, Kim DH, Jang JY, Hwang SY, Kim M, Lim HS, Yoon JH, Chung HY et al: Apigenin-induced apoptosis is enhanced by inhibition of autophagy formation in HCT116 human colon cancer cells. Int J Oncol 44: 1599-1606, 2014.

29. Zhang L, Cheng X, Gao Y, Zheng J, Xu Q, Sun Y, Guan H, $\mathrm{Yu} \mathrm{H}$ and Sun Z: Apigenin induces autophagic cell death in human papillary thyroid carcinoma BCPAP cells. Food Funct 6: 3464-3472, 2015.

30. Zhu Y, Mao Y, Chen H, Lin Y, Hu Z, Wu J, Xu X, Xu X, Qin J and Xie L: Apigenin promotes apoptosis, inhibits invasion and induces cell cycle arrest of T24 human bladder cancer cells. Cancer Cell Int 13: 54, 2013.

31. Lee SR, Park JH, Park EK, Chung CH, Kang SS and Bang OS: Akt-induced promotion of cell-cycle progression at $\mathrm{G}_{2} / \mathrm{M}$ phase involves upregulation of NF-Y binding activity in PC12 cells. J Cell Physiol 205: 270-277, 2005.

32. Hennessy BT, Smith DL, Ram PT, Lu Y and Mills GB: Exploiting the PI3K/AKT pathway for cancer drug discovery. Nat Rev Drug Discov 4: 988-1004, 2005.

33. Lin HP, Jiang SS and Chuu CP: Caffeic acid phenethyl ester causes $221^{\text {Cipl }}$ induction, Akt signaling reduction, and growth inhibition in PC-3 human prostate cancer cells. PLoS One 7: e31286, 2012. 
34. Erdogan S, Doganlar O, Doganlar ZB, Serttas R, Turkekul K, Dibirdik I and Bilir A: The flavonoid apigenin reduces prostate cancer $\mathrm{CD} 44^{+}$stem cell survival and migration through PI3K-Akt/NF-кB signaling. Life Sci 162: 77-86, 2016.

35. Renehan AG, Booth C and Potten CS: What is apoptosis, and why is it important? BMJ 322: 1536-1538, 2001.

36. Hassen S, Ali N and Chowdhury P: Molecular signaling mechanisms of apoptosis in hereditary non-polyposis colorectal cancer. World J Gastrointest Pathophysiol 3: 71-79, 2012.

37. Boulares AH, Yakovlev AG, Ivanova V, Stoica BA, Wang G, Iyer S and Smulson M: Role of poly(ADP-ribose) polymerase (PARP) cleavage in apoptosis. Caspase 3-resistant PARP mutant increases rates of apoptosis in transfected cells. J Biol Chem 274 22932-22940, 1999.

38. Seo HS, Choi HS, Kim SR, Choi YK, Woo SM, Shin I, Woo JK, Park SY, Shin YC and Ko SG: Apigenin induces apoptosis via extrinsic pathway, inducing p53 and inhibiting STAT3 and NFKB signaling in HER2-overexpressing breast cancer cells. Mol Cell Biochem 366: 319-334, 2012

39. Shukla S, Fu P and Gupta S: Apigenin induces apoptosis by targeting inhibitor of apoptosis proteins and $\mathrm{Ku} 70$-Bax interaction in prostate cancer. Apoptosis 19: 883-894, 2014.

40. Das S, Das J, Samadder A, Boujedaini N and Khuda-Bukhsh AR Apigenin-induced apoptosis in A375 and A549 cells through selective action and dysfunction of mitochondria. Exp Biol Med (Maywood) 237: 1433-1448, 2012.

41. Choi KY, Chang K, Pickel JM, Badger JD II and Roche KW: Expression of the metabotropic glutamate receptor 5 (mGluR5) induces melanoma in transgenic mice. Proc Natl Acad Sci USA 108: 15219-15224, 2011.
42. Khan AJ, Wall B, Ahlawat S, Green C, Schiff D, Mehnert JM, Goydos JS, Chen S and Haffty BG: Riluzole enhances ionizing radiation-induced cytotoxicity in human melanoma cells that ectopically express metabotropic glutamate receptor 1 in vitro and in vivo. Clin Cancer Res 17: 1807-1814, 2011.

43. Lee HJ, Wall BA, Wangari-Talbot J, Shin SS, Rosenberg S, Chan JLK, Namkoong Jin, Goydos JS and Chen S: Glutamatergic pathway targeting in melanoma: Single-agent and combinatorial therapies. Clin Cancer Res 17: 7080-7092, 2011.

44. Gelb T, Pshenichkin S, Hathaway HA, Grajkowska E, Dalley CB, Wolfe BB and Wroblewski JT: Atypical signaling of metabotropic glutamate receptor 1 in human melanoma cells. Biochem Pharmacol 98: 182-189, 2015

45. Lee HJ, Wall BA, Wangari-Talbot $J$ and Chen S: Regulation of mGluR1 expression in human melanocytes and melanoma cells. Biochim Biophys Acta 1819: 1123-1131, 2012.

46. Song Z, He CD, Liu J, Sun C, Lu P, Li L, Gao L, Zhang Y, Xu Y, Shan $\mathrm{L}$ et al: Blocking glutamate-mediated signalling inhibits human melanoma growth and migration. Exp Dermatol 21: 926-931, 2012

47. Tanimura S, Uchiyama A, Watanabe K, Yasunaga M, Inada Y, Kawabata T, Iwashita K, Noda S, Ozaki K and Kohno M: Blockade of constitutively activated ERK signaling enhances cytotoxicity of microtubule-destabilizing agents in tumor cells. Biochem Biophys Res Commun 378: 650-655, 2009. 